\title{
A NEW CLASSIFICATION PROPOSAL OF COEFFICIENTS OF VARIATION FOR MORPHO-AGRONOMIC TRAITS IN SNAP BEANS
}

Douglas Mariani Zeffa ${ }^{1}$, (D) Luiz Júnior Perini ${ }^{2}$, (D) Leonel Vinicius Constantino $^{2}$, (D) Gustavo Henrique Freiria ${ }^{3}$, (D) Leandro Simões Azeredo Gonçalves $^{2}$

1 Universidade Estadual de Maringá, Department of Agronomy, Paraná, Brazil;

2 Universidade Estadual de Londrina, Department of Agronomy, Paraná, Brazil;

3 Universidade do Estado de Minas Gerais, Unidade Ituiutaba, Minas Gerais, Brazil.

*Corresponding author: Douglas Mariani Zeffa (douglas.mz@hotmail.com).

\begin{abstract}
The aim of this study was to present a classification proposal for coefficients of variation $(\mathrm{CV})$ of morpho-agronomic traits in snap bean. The CV values were obtained from 53 studies related with snap beans published between 1987 and 2018, yielding a total of 372 data. The following traits were assessed: commercial pod yield, total pods yield, pod length, pod diameter, mean pod weight, number of pods per plant, number of seeds per pod and fiber pod content. Since verified the normal distribution of data, the $\mathrm{CV}$ were classified by values of mean $(\mathrm{m})$ and standard deviation $(\mathrm{sd})$ as: low $[\leq(\mathrm{m}-$ $1 \mathrm{sd})]$; medium $[(\mathrm{m}-1 \mathrm{sd})<\mathrm{CV} \leq(\mathrm{m}+1 \mathrm{sd})$; high $[(\mathrm{m}+1 \mathrm{sd})<\mathrm{CV} \leq(\mathrm{m}+2 \mathrm{sd})]$ and very high $[>(m+2 s d)]$. The results indicated that the pod diameter, pod length, mean pod weight and number of seeds per pods are variables weakly influenced by the environment. In contrast, the other traits related had the highest range of CV. The classification proposed in the present study provides a useful tool for researchers interested in estimating the accuracy of their experiments.
\end{abstract}

Keywords: accuracy, experimental error, experimental precision, green beans, Phaseolus vulgaris L. 


\section{Introduction}

Snap bean (Phaseolus vulgaris L.) is an important vegetable worldwide, with estimated world production at around 21 million tons (FAO, 2019). The consumption of snap beans may be in form of seeds or immature pods, considered an excellent food source of fibers, vitamins, minerals, carbohydrates and proteins (Yuan et al., 2017; Fukuji et al., 2019). Due to the great importance of snap beans as human food, becomes relevant the confidence in the precision of agricultural experiments, such as development of new cultivars, resistance or tolerance to the crop pests and diseases, adaptation and stability in crop areas, beyond genotypes acceptance by bean consumers.

The proper estimation of experimental precision is a common aim among researchers, contributing to decrease experimental error (Ribeiro et al., 2017). The coefficient of variation (CV) has been used by researchers to describe the accuracy of their experiments (Kuehl and Kuehl, 2000), since it gives a general indication of the variation levels using the standard deviation as a fraction of the mean. In the sense, PimentelGomes (2009) proposed a classification of the CV's obtained from agricultural studies, which were classified as low for values lower than $10 \%$, moderate for values from 10 to $20 \%$, high for values higher than 20 up to $30 \%$ and very high for values higher than $30 \%$.

Despite it is commonly used, the classifycation proposed by Pimentel-Gomes (2009) is considered very wide, besides disregard the intrinsic factors of each crop and their traits evaluated. In the sense, aiming to classify the specific CV's for each crop, Garcia (1989) proposed a new classification methodology based on data from previous experiments. To do so, Garcia (1989) used the CV's from 146 experiments of different species of Eucalyptus, classifying them based on their mean values $(\mathrm{m})$ and standard deviation (sd) as: low $[\leq(\mathrm{m}-1 \mathrm{sd})]$; medium $[(\mathrm{m}-1 \mathrm{sd})<\mathrm{CV} \leq(\mathrm{m}+1 \mathrm{sd})$; high $[(\mathrm{m}$ $+1 \mathrm{sd})<\mathrm{CV} \leq(\mathrm{m}+2 \mathrm{sd})]$ and very high $[>(\mathrm{m}+$ 2sd)].

In the sense, based on Garcia (1989) method, several studies have been performed to investigate the classification of CV's in corn (Fritsche-Neto et al., 2012), rice (Costa et al., 2002), papaya (Ferreira et al., 2016), sugarcane (Couto et al., 2013) and eucalyptus (Mora and Arriagada, 2016). The aim of this study was to present a classification for coefficient of variation in snap bean traits, since there is not yet a specific proposal for this crop.

\section{Material and methods Data collection and evaluated traits}

The CV values were obtained from 53 studies related with snap beans published between 1987 and 2018, yielding a total of 372 data. In these studies, different snap bean genotypes were used in experimental designs completely randomized or randomized blocks, using between three and five replicates. The following traits were assessed: commercial pod yield (CPY), total pods yield (TPY), pod length (PL), pod diameter (PD), mean pod weight (MPW), number of pods per plant (NPP), number of seeds per pod (NSP) and fiber pod content (FPC).

\section{Classification of coefficients of variation}

The Kolmogorov-Smirnov test modified by Lilliefors (1967) was used to verify the adherence of the data to the normal distribution. The arithmetic mean (m), standard deviation (sd) and maximum and minimum values from the review were evaluated for the present study proposal based on Garcia (1989) method, classifying the $\mathrm{CV}$ range as low $[\mathrm{CV} \leq(\mathrm{m}-1 \mathrm{sd})]$; medium $[(\mathrm{m}-$ $1 \mathrm{sd})<\mathrm{CV} \leq(\mathrm{m}+1 \mathrm{sd}) ; \operatorname{high}[(\mathrm{m}+1 \mathrm{sd})<\mathrm{CV} \leq(\mathrm{m}$ $+2 \mathrm{sd})$ and very high $[\mathrm{CV}>(\mathrm{m}+2 \mathrm{sd})]$.

\section{Expected and observed frequencies}

The expected and observed frequencies of CV's were verified, besides the frequencies observed by Pimentel-Gomes (2009). Within normal distribution of the data, $68.27 \%$ of the CV's are included between $\mathrm{m} \pm 1 \mathrm{sd}$; $95.45 \%$ of CV's between $\mathrm{m} \pm 2$ sd and $99.73 \%$ of CV's between $\mathrm{m} \pm 3 \mathrm{sd}$. Thus, the expected CV's frequencies that correspond to the ranges of classification are 15.86, 68.27, 13.59 and $2.28 \%$, respectively. 


\section{Statistical analyses}

Statistical analyses were carried using the software R (R Core Team, 2019) thought nortest (Gross and Ligges, 2012) and ggplot2 (Wickham, 2016) packages.

\section{Results and discussion Normality and amplitude of the data}

All traits presented normal distribution by Lilliefors test (1967) at a significance level of 5\%
(Figure1). The verification of the normal distribution of the data is important, since it is required according to the classification criteria of Garcia (1989). When data has not been normally distributed, Costa et al. (2002) suggested the use of median and pseudo-sigma statistics instead of the mean and standard deviation, respectively. Furthermore, these authors verified that when there is normal distribution of the data, both methodologies provide equivalent classification.

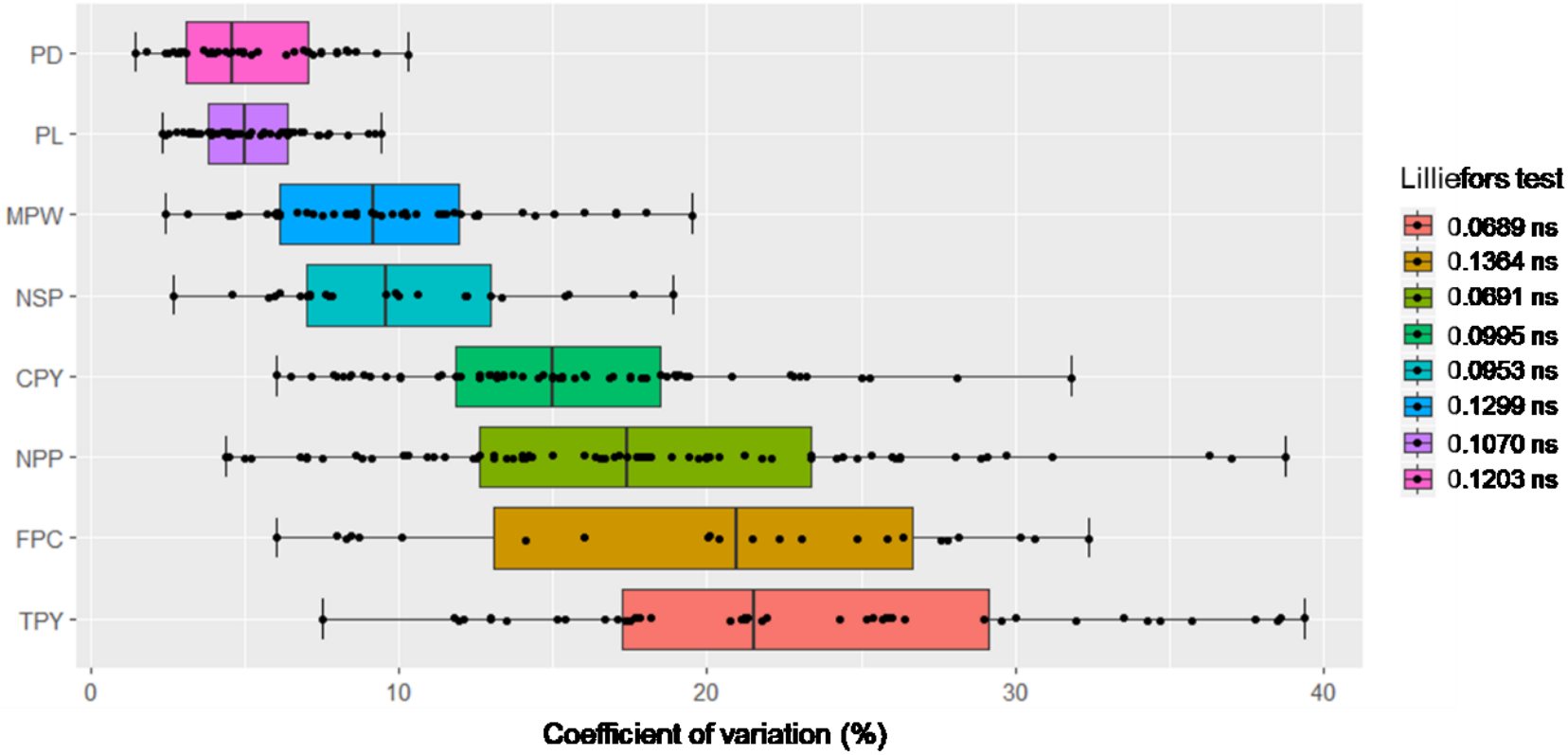

Figure 1. Box plot and Lilliefors test (1967) of the coefficients of variation for eight traits obtained from snap beans (Phaseolus vulgaris L.) studies. Commercial pod yield (CPY), total pod yield (TPY), pod length (PL), number of seeds per pod (NSP), number of pods per plant (NPP), mean pod weight (MPW), pod diameter (PD) and fiber pod content (FPC). ns $=$ not significant at the $5 \%$ level by Lilliefors test.

Based on the maximum and minimum values (Figure 1), wide amplitude of the data was observed both among and within the traits, indicating the influence of environmental factors on the evaluated traits. It should be noted that the $\mathrm{CV}$ values were determined based on field trials where the treatments were of different natures such as types and rates of fertilizer (Gomes et al., 2017) and assessments applied to genetic improvement (Sousa et al., 2017). Thus, the classification of CV for each trait is necessary to promote a proper precision evaluation of these experiments. Similar results were observed in the determination of classification ranges of CV's in plants species (Mora and Arrigada, 2016; Ferreira et al., 2016).

\section{Ranges of classification}

The studied traits had specific ranges of classification (Table 1), different from those proposal suggested by Pimentel-Gomes (2009), except for the traits CPY and NPP, which were similar for both classification proposals. The frequencies expected and observed, according to the criteria proposed by Garcia (1989) and Pimentel-Gomes (2009) (Table 2), were estimated considering that the $\mathrm{CV}$ data had normal distribution. Hence, it is expected that most values are distributed close to the mean, and low frequency of extreme values.

The TPY presented the ranges of classification for CV higher than for the CPY (Table 2), indicating a great environment influence on the TPY. These results can be justified due to the pods selection according to the commercial standard, with discard the nonstandard pods, which promote a high homogeneity of pods and, consequently, lower CV values (Myers and Bagget, 2013). 
Table 1. Classification of coefficient of variation (CV) for eight traits obtained from snap beans (Phaseolus vulgaris L.) studies.

\begin{tabular}{ccccc}
\hline \multirow{2}{*}{ Traits $^{1}$} & \multicolumn{4}{c}{ Coefficient of variation (\%) } \\
\cline { 2 - 4 } & Low & Medium & High & Very high \\
\hline CPY & $\leq 9.7$ & $9.7<\mathrm{CV} \leq 20.8$ & $20.8<\mathrm{CV} \leq 26.3$ & $>26.3$ \\
TPY & $\leq 14.8$ & $14.8<\mathrm{CV} \leq 31.6$ & $31.6<\mathrm{CV} \leq 40.0$ & $>40.0$ \\
\hline PL & $\leq 3.3$ & $3.3<\mathrm{CV} \leq 7.0$ & $7.0<\mathrm{CV} \leq 8.8$ & $>8.8$ \\
\hline NSP & $\leq 5.7$ & $5.7<\mathrm{CV} \leq 14.0$ & $14.0<\mathrm{CV} \leq 18.2$ & $>18.2$ \\
\hline NPP & $\leq 9.9$ & $9.9<\mathrm{CV} \leq 25.5$ & $25.5<\mathrm{CV} \leq 33.3$ & $>33.3$ \\
\hline MPW & $\leq 5.5$ & $5.5<\mathrm{CV} \leq 13.6$ & $13.6<\mathrm{CV} \leq 17.7$ & $>17.7$ \\
\hline PD & $\leq 2.8$ & $2.8<\mathrm{CV} \leq 7.4$ & $7.4<\mathrm{CV} \leq 9.7$ & $>9.7$ \\
\hline FPC & $\leq 11.8$ & $11.8<\mathrm{CV} \leq 28.7$ & $28.7<\mathrm{CV} \leq 36.4$ & $>36.4$ \\
\hline CPY
\end{tabular}

1 CPY: commercial pod yield, TPY: total pod yield, PL: pod length, NSP: number of seeds per pod, NPP: number of pods per plant, MPW: mean pod weight, PD: pod diameter and FPC: fiber pod content.

2 The CV's were classified by values of mean $(\mathrm{m})$ and standard deviation $(\mathrm{sd})$ as: low $[\leq(\mathrm{m}-1 \mathrm{sd})]$; medium $[(\mathrm{m}-1 \mathrm{sd})$ $<\mathrm{CV} \leq(\mathrm{m}+1 \mathrm{sd})$; high $[(\mathrm{m}+1 \mathrm{sd})<\mathrm{CV} \leq(\mathrm{m}+2 \mathrm{sd})]$ and very high $[>(\mathrm{m}+2 \mathrm{sd})]$.

Table 2. Observed $\left(\mathrm{F}_{\mathrm{o}}\right)$ and expected frequencies $\left(\mathrm{F}_{\mathrm{e}}\right)$ of coefficient of variation for eight traits obtained from snap beans (Phaseolus vulgaris L.) studies according to Garcia (1989) and Pimentel-Gomes (2009).

\begin{tabular}{|c|c|c|c|c|c|}
\hline \multirow{2}{*}{ Method } & \multirow{2}{*}{ Traits $^{1}$} & \multicolumn{4}{|c|}{$F_{o}(\%)$} \\
\hline & & Low & Medium & High & Very high \\
\hline \multirow{8}{*}{ Garcia (1989) } & CPY & 18.46 & 67.69 & 12.31 & 1.54 \\
\hline & TPY & 15.91 & 63.64 & 18.18 & 2.27 \\
\hline & $\mathrm{PL}$ & 16.00 & 68.00 & 10.00 & 6.00 \\
\hline & NSP & 12.00 & 72.00 & 12.00 & 4.00 \\
\hline & NPP & 15.58 & 67.53 & 14.29 & 2.60 \\
\hline & MPW & 10.87 & 71.74 & 13.04 & 4.35 \\
\hline & PD & 17.07 & 63.41 & 17.07 & 2.44 \\
\hline & FPC & 21.00 & 66.50 & 9.33 & 3.17 \\
\hline \multirow{8}{*}{$\begin{array}{l}\text { Pimentel-Gomes } \\
\text { (2009) }\end{array}$} & CPY & 18.46 & 66.15 & 10.77 & 1.54 \\
\hline & TPY & 2.27 & 34.09 & 43.18 & 20.45 \\
\hline & $\mathrm{PL}$ & 100.00 & 0.00 & 0.00 & 0.00 \\
\hline & NSP & 60.00 & 40.00 & 0.00 & 0.00 \\
\hline & NPP & 15.58 & 53.25 & 27.27 & 5.19 \\
\hline & MPW & 56.52 & 43.48 & 0.00 & 0.00 \\
\hline & PD & 97.56 & 2.44 & 0.00 & 0.00 \\
\hline & FPC & 20.83 & 16.67 & 50.00 & 12.50 \\
\hline$F_{e}(\%)$ & & 15.86 & 68.27 & 13.59 & 2.28 \\
\hline
\end{tabular}

${ }^{1} \mathrm{CPY}$ : commercial pod yield, TPY: total pod yield, PL: pod length, NSP: number of seeds per pod, NPP: number of pods per plant, MPW: mean pod weight, PD: pod diameter and FPC: fiber pod content.

In relation to the $\mathrm{PL}$, according to Pimentel-Gomes (2009) proposal, 100\% of the $\mathrm{CV}$ would be considered low and none them would be classified as medium, high or very high (Table 2), therefore, it may generate a false indication of high experimental precision and, consequently, generating incorrect conclusions. Similar results were observed by Couto et al. (2013), Mora and Arrigada (2016) and Ferreira et al. (2016).

For the traits MPW, NSP and PD, none of the $\mathrm{CV}$ observed would be classified as high or very high by Pimentel-Gomes (2009) proposal
(Table 2). Therefore, the $\mathrm{CV}$ classification proposal by Pimentel-Gomes (2009) would not be the most proper for these traits due a low environment influence on precision of the experiments. In contrast, according to PimentelGomes (2009) classification proposal, $50 \%$ of CV's should be classified as high and $12.5 \%$ as very high, underestimating the $\mathrm{CV}$ ranges for the FPC.

Oliveira et al. (2009) proposed a classification of the CV's in common bean. Comparing the ranges obtained by Oliveira et al. (2009) with the proposals of the present study, 
similar ranges are observed for the NPP and NSP. These results can be explained by the fact that snap beans belong to the same botanical species of common bean (Phaseolus vulgaris L.), in which a great part of the distinguishing traits is related to the occurrence of mutations in loci that control quality traits of pods (Myers and Bagget, 2013).

In general, when there is not a classification for a particular species and traits, the researchers compare the $\mathrm{CV}$ values of their experiments with the ones suggested by Pimentel-Gomes (2009). Thus, as there is not a previous report for the traits of snap beans, the means of the CV's for PD (5.14\%), PL (5.21\%), MPW $(9.63 \%)$ and NSP $(9.89 \%)$ were considered low. This indicates most of the variables measuredin snap bean are stable or weakly affected by the environment, except the CPY (15.29\%), NPP (17.72\%), FPC (20.05\%) and TPY (23.27\%), which was classified as moderate. Therefore, the present classification is recommended to guide researchers on the validity of their results and may lead to correct conclusions in studies involving these variables in snap beans.

\section{Conclusion}

The proposal suggested in this study presents a more proper classification of coefficient of variation for snap bean traits, allowing an experimental precision approach specific for this crop. The ranges of values of the coefficient of variation differ among the different variables, showing wide variation, justifying the need to use specific evaluation range for each character. The proposed classification provides a useful tool for researchers interested in estimating the accuracy of their experiments involving snap beans traits.

\section{Acknowledgments}

We are grateful to Coordenação de Aperfeiçoamento de Pessoal de Nível Superior (CAPES) which provided the financial support necessary to the development of this research.

\section{References}

COSTA, NHAD; SERAPHIN, JC; ZIMMERMANN, FJP. 2002. A new method of variation coefficient classification for up landrace crop. Pesquisa Agropecuária Brasileira, 37(3):243249.

COUTO, MF; PETERNELLI, LA; BARBOSA, MHP. 2013. Classification of the coefficients of variation for sugarcane crops. Ciência Rural, 43(6):957-961.

FAO - Food and Agriculture Organization. 2019. Statistical databases - Agriculture.

FERREIRA, JP; SCHMILDT, ER; SCHMILDT, O; CATTANEO, LF; ALEXANDRE, RS; CRUZ, CD. 2016. Comparison of methods for classification of the coefficient of variation in papaya. Revista Ceres, 63(2):138-144.

FRITSCHE-NETOR; VIEIRA, RA; SCAPIM, CA; MIRANDA, GV; REZENDE, LM. 2012. Updating the ranking of the coefficients of variation from maize experiments. Acta Scientiarum.Agronomy, 34(1):99-101.

FUKUJI, AYS; CONSTANTINO, LV; ZEFFA, DM; ANDRADE, FAD; SILVA, MBD; GONÇALVES, LSA. 2019. Amino acid concentration, total phenolic compound content and antioxidantactivity of snap bean genotypes. Brazilian Journal of Food Technology, 22:1-6.

GARCIA, CH. 1989.Tabelas para classificação de coeficientes de variação. 1st, Piracicaba: Instituto de Pesquisa e Estudos Florestais. Brazil. 
GOMES, GR; FURLAN, FF; FREIRIA, GH; GONÇALVES, LSA; TAKAHASHI, LSA. 2017. Production components and yield of bushing snap bean in conventional and organic production systems. Semina: Ciências Agrárias, 38(5):3353-3361.

GROSS, J; LIGGES, U. 2012. Nortest: Tests for Normality. R package version 1.0-2.

KUEHL, RO; KUEHL, RO. 2000. Design of experiments: statistical principles of research design and analysis. Pacific Grove, CA: Duxbury/Thomson Learning. 666 p.

LILLIEFORS, HW. 1967. On the Kolmogorov-Smirnov test for normality with mean and variance unknown. Journal of the American Statistical Association, 62(318):399-402.

MYERS, JR; BAGGET, JR. 2013. Improvement of snap bean. In: Singh, S.P. (Ed.). Common bean improvement in the twenty-first century. Springer Science \& Business Media. 405 p.

MORA, F; ARRIAGADA, O. 2016. A classification proposal for coefficients of variation in Eucalyptus experiments involving survival, growth and wood quality variables. Bragantia, 75(3):263-267.

OLIVEIRA, RL; MUNIZ, JA; ANDRADE, MJBD; REIS, RLD. 2009. Experimental precision on beancrop experiments. Ciência e Agrotecnologia, 33(1):113-119.

PIMENTEL-GOMES, F. 2009. Curso de estatística experimental. 12a . ed., Fundação de Estudos Agrários Luiz de Queiroz. 451 p.

R Core Team. 2019. R: A Language and Environment for Statistical Computing. Available from URL.

RIBEIRO, ND; STECKLING, SDM; MAZIERO, SM; SILVA, MJ; KLÄSENER, GR; CASAGRANDE, CR. 2017. Experimental precision of grain yield components and selection of superior common bean lines. Euphytica, 213(12):1-11.

SOUSA, CMB; GRAVINA, GA; VIANA, AP; DAHER, RF; SOUZA, CLM. 2017. Selection of snap bean $F_{2}$ progenies for production using the REML/BLUP methodology. Horticultura Brasileira, 35(1):33-40.

WICKHAM, H. 2016. ggplot2: elegantgraphics for data analysis. Springer. 260 p.

YUAN, M; RUARK, MD; BLAND, WL. 2017. A simple model for snap bean (Phaseolus vulgaris L.) development, growth and yield in response to nitrogen. Field Crops Research, 211(1):125136. 